\title{
ELASTISITAS PENERIMAAN PENDAPATAN ASLI DAERAH (PAD) TERHADAP PRODUK DOMESTIK REGIONAL BRUTO (PDRB) DI KABUPATEN SUMENEP
}

\author{
Oleh: \\ Karman Rasid \\ Alumni Jurusan Ekonomi Pembangunan FEB UMM \\ Dwi Eko waluyo \\ Fakultas Ekonomi \& Bisnis Universitas Muhammadiyah Malang \\ E-mai/No.Hp: dewaruci@yahoo.com
}

\begin{abstract}
The research is quantitative descriptive research from 2005/2006-2008/2009, and this research uses non-participant observation. The research purpose is to find out how large regional original income elasticity to Regional Gross Domestic Product in range time 2005/2006-2008/2009 also to find out how large task and retribution elasticity to Sumenep Regency Gross Domestic Product. Research result from 2005/20062008/2009 shows: (1) Regional Original Income elasticity to Regional Gross Domestic Product of Sumenep Regency has average 1,84 \%, (3) Retribution elasticity to Sumenep Regency Regional Gross Domestic Product average is 1,79 \%, (4) Regional Original Income elasticity to the amount of Sumenep Regency inhabitants amount has average $310,56 \%$, (5) Task elasticity to the amount of Sumenep Regency inhabitants has average 707,13\%, and (6) Retribution elasticity to average inhabitants amount is $797,13 \%$. From equation above, it can be concluded that regional original income to Regional Gross Domestic Product of Sumenep Regency is quite sense from year 2005/2006- 2008/2009, that's why it needed to be defended. While the suggestion is improving regional economic growth and add retribution and tax objects also intensification of retribution and task payment system.
\end{abstract}

Keywords: Original Regional Income, Sumenep Regency, Regional Gross Domestic Product, Elastic

\begin{abstract}
Abstrak
Penelitian ini merupakan penelitian deskriptif kuantitatif dari tahun 2005/20062008/2009, dan penelitian ini menggunakan observasi non partisipan.Tujuan penelitian ini adalah untuk mengetahui seberapa besar Elastisitas pendapatan asli daerah terhadap PDRB dalam kurun waktu 2005/2006- 2008/2009 serta untuk menegtahui seberapa besar elastisitas pajak dan retribusi terhadap PDRB kabupaten Sumenep.Hasil dari penelitian yakni dari tahun 2005/2006- 2008/2009 sebagai berikut: (1) Elastisitas penerimaan PAD terhadap PDRB kabupaten Sumenep rata-rata pertumbuhannya adalah 1,88\%, (2) Elastisitas pajak terhadap PDRB kabupaten Sumenep rata-ratanya adalah 1,84\%, (3) Elastisitas retribusi terhadap PDRB kabupaten Sumenep rata-ratanya adalah 1,79\%, (4) Elastisitas penerimaan PAD terhadap jumlah penduduk kabupaten Sumnep rata-ratanya adalah 310,56 \%, (5)
\end{abstract}


Elastisitas pajak terhadap jumlah penduduk kabupaten Sumenep rata-ratanya adalah $707,13 \%$, dan (6) Elastisitas retribusi terhadap jumlah penduduk rata-ratanya adalah 797,13 \%.Dari perhitungan diatas dapat disimpulkan bahwa penerimaan PAD terhadap PDRB kabupaten Sumenep cukup peka dari tahun 2005/2006- 2008/2009, karena itu perlu di pertahankan. Sedangkan saran yaitu meningkatkan pertumbuhan Ekonomi Daerah serta menambah obyek retribusi dan Pajak serta intensifikasi sistem pemungutan retribusi dan pajak.

Kata Kunci: Pendapatan Asli Daerah, Kabupaten Sumenep, Produk Domestik Regional Bruto, Elastis.

PENDAHULUAN

Pembangunan di Indonesia masih terus dilaksanakan walaupun sekarang ini keadaan negara sedang tidak stabil. Pembangunan ini meliputi segala bidang aspek kehidupan, yang pada hakekatnya menciptakan suatu masyarakat yang adil dan makmur bagi bangsa Indonesia. Hal ini sesuai dengan ketentuan yang tercantum dalam ketetapan MPR No. 11/MPR/1993 tentang GBHN yaitu Pembangunan Nasional bertujuan untuk mewujudkan suatu masyarakat adil dan makmur yang merata, materiil, spiritual berdasarkan Pancasila dan UUD 1945 dalam wadah negara kesatuan RI yang merdeka, bersahabat, tertib dan damai, upaya mewujudkan kesejahteraan rakyat agar semakin adil dan merata harus terus ditingkatkan, pertumbuhan ekonomi harus ditingkatkan melalui upaya nyata dalam bentuk perbaikan pendapatan asli daerah, sperti pajak, retribusi untuk mensejahterahkan masayarakat.
Pembangunan yang berhasil dirasakan oleh rakyat sebagai perbaikan tingkat taraf hidup pada segenap golongan masyarakat akan meningkatnya kesadaran mereka akan arti penting pembangunan dan mendorong masyarakat berperan aktif dalam pembangunan.Di dalam TAP MPR No. IV/MPR/2000 ditegaskan bahwasanya "kebijakan desentralisasi Daerah diarahkan untuk mencapai peningkatan pelayanan publik dan pengembangan kreativitas Pemda, keselarasan hubungan antara Pusat dan Daerah serta antar Daerah itu sendiri dalam kewenangan dan keuangan untuk menjamin peningkatan rasa kebangsaan, demokrasi dan kesejahteraan serta penciptaan ruang yang lebih luas bagi kemandirian Daerah”. Sebagai konsekuensi dari pemberian otonomi yang luas maka sumber-sumber keuangan telah banyak bergeser ke Daerah baik melalui 
perluasan basis pajak (taxing power) maupun dana perimbangan.

Berdasarkan pemikiran diatas, penelitian ini mengeksplorasi bagaimana kontribusi pajak dan retribusi daerah terhadap PDRB. Hasil eksplorasi tersebut kemudian akan dilakukan pengujian apakah terdapat perbedaan peranan (kontribusi) pajak dan retribusi daerah yang signifikan diantara kabupaten/kota di Jawa Timur. Hal ini bertujuan untuk menguji dan membuktikan apakah pemda di Jawa Timur cukup mengandalkan pajak dan retribusi daerah terhadap struktur (PAD). Dari uraian diatas maka peneliti tertarik untuk melakukan penelitian mengenai "Elastisitas Penerimaan Pendapatan Asli Daerah (PAD) Terhadap Produk Domestik Regional Bruto (PDRB) Kabupaten Sumenep”.

Pendapatan asli daerah adalah salah dari sumber pendapatan daerah. Yang di maksud Pendapatan Asli Derah adalah penerimaan yang di peroleh daerah dari sumber-sumber pendapatan didalam wilayahnya sendiri. Pendapatan Asli Daerah tersebut di pungut berdsarakan peraturan daerah yang sesuai dengan peraturan perundangundangan yang berlaku di Indonesia.
Menurut Halim dan Nasir (2006:44), Pendapatan Asli Daerah “ pendapatan yang di peroleh daerah yang di pungut berdasarkan peraturan derah dengan peraturan perundangundangan." Jenis- jenis Pendapatan Asli Daerah( PAD) Kalasifikasi PAD yang terbaru berdasarkan Permendakri 13/2006 adalah terdiri dari: Pajak daerah retribusi daerah, hasil pengelolaan kekayaaan daerah yang di pisahkan dan lain-lain pendapatan asli daerah yang sah. Menurut Halim (2004:67) Pendapatan Asli Daerah di pisahkan menjadi empat pendapatan, yaitu : pajak daerah, retribusi daerah, hasil perusahaan milik daerah dan hasil pengelolaan kekayaan milik daerah yang di pisahkan, lain- lain PAD yang sah. Klasifikasi PAD yang di nyatakan oleh Halim adalah sesuai klasifikasi Kepmendagri 29/2002. Jenis- jenis pajak Derah Kabupaten/atau kota.

Menurut Undang -undang 34 Tahun 2000 Tentang Pajak Daerah dan Retribusi Daerah jenis Pendapatan pajak Kabupaten/kota tersusun dari Pajak Hotel, Pajak, Restoran, Pajak Hiburan,Pajak Reklame Pajak penerangan Jalan, Pajak pengambilan Bahan galian Golongan C dan Pajak Parkir. 
Menurut Andini (1991:2) yang telah di terjemahkan oleh $\mathrm{R}$ Santoso Brotodiharjo dalam buku " Pengantar Ilmu Hukum Pajak" Pajak adalah iuran kepada Negara (yang dapat di paksakan) yang terutang oleh yang wajib membayarnya menurut peraturan-peraturan, dengan tidak mendapat prestasi kembali, yang langsung di tunjuk, dan yang gunanya adalah untuk membiayai pengeluaranpengeluaran umum berhubung dengan tugas Negara yang menyelenggarakannya pemerintah.

Dari penegertian -penegertian tersebut dapat disimpulkan bahwa ciriciri yang melekat pada pengertian pajak, adalah:.Pajak di pungut berdasarkan undang-undang serta aturan pelaksanannya yang sifatnya dapat di paksakan. Dalam pembayaran pajak tidak dapat di tunjukkan adanya kontraprestasi individual oleh pemerintah. Pajak dipungut oleh Negara baik pemerintah pusat maupun daerah. Pajak diperuntukkan bagi pengeluaranpengeluaran pemerintah, yang bila dari pemasukannya masih mendapat surplus, di pergunakan untuk membiayai publik invesmment. Pajak dapat pula mempunyai tujuan selain budgeter, yaitu mengatur.
Produk Domestik Regional Bruto (PDRB) menggambarkan tingkat kegiatan perekonomian suatu daerah baik yang dilakukan oleh masyarakat, swasta maupun pemerintah dalam suatu periode tertentu (biasanya satu tahun). Seluruh hasil produksi atau output yang diciptakan oleh suatu daerah tercatat dalam Produk Domestik Regional Bruto (PDRB), sehingga secara tidak langsung dapat digunakan sebagai indikator menilai hasil kegiatan pembangunan daerah. Dari hasil Produk Domestik Regional Bruto (PDRB) dapat dilihat perkembangan sektor yang menjadi komponen struktur ekonomi.

Selain dari definisi di atas, ada bebarapa konsep untuk memahami mekanisme perhitungan Produk Domestik Regional Bruto (PDRB), dengan Pendekatan produksi (product approach) Pendekatan pendapatan (income approach), Pendekatan pengeluaran (spending approach), Pendekatan alokasi (distribution approch)

\section{METODE PENELITIAN}

Penelitian ini berjudul "elastisitas Penerimaan Pendapatan Asli Daerah (PAD) Terhadap Produk Domestik Regional Bruto (PDRB) di Kabupaten 
Sumenep”. Dari judul tersebut maka penelitihan dilakukan di Kabupaten Sumenep. Penelitian ini menggunakan metode deskriptif kuantitatif .penelitian deskriptif kuantitatif suatu bentuk penelitian yang paling dasar dengan menggunakan instrumen-instrumen formal, standar dan bersifat mengukur (Sukmadinata, 2010:95). Penelitian ini di sajikan dalam bentuk tabel dan angka dengan analisis sederhana.

Data yang di kumpulkan dalam penelitian ini adalah data sekunder.

Tabel 1. Perkembangan Pendapatan Asli Daerah Kabupaten Sumenep Tahun 2005/2006 - 2008/2009
Data skunder yaitu data yang dikumpulkan, diolah dan di sajikan oleh pihak lain atau instansi terkait.Adapun data yang di teliti berasal dari BPS Jawa Timur Surabaya.

\section{PEMBAHASAN}

Berdasarkan hasil analisis deskriptif kuantitatif yang dihitung dengan menggunakan program Excel dapat di susun ringkasan hasil analisis deskriptif kuantitatif sederhana terlihat di tabel 2

\begin{tabular}{|c|c|c|c|c|c|c|c|}
\hline Tahun & PAD & Pertumbuhan PAD (\%) & & PDRB & Pertumbuhan PDRB & Elastisitas (\%) & Keterangan \\
\hline 2005 & Rp32.964.574.000 & & $\mathrm{Rp}$ & 4.376 .237 .910 .000 & & & \\
\hline 2006 & Rp38.991.459.000 & 18,28 & Rp & 4.555 .422 .120 .000 & 4,09 & 4,47 & Elastis \\
\hline 2007 & Rp40.923.651.000 & 4,96 & $\mathrm{Rp}$ & 4.765 .087 .090 .000 & 4,60 & 1,08 & Elastis \\
\hline 2008 & Rp42.795.564.000 & 4,57 & $\operatorname{Rp}$ & 4.960 .417 .330 .000 & 4,10 & 1,12 & Elastis \\
\hline 2009 & Rp44.292.310.000 & 3,50 & $\mathrm{Rp}$ & 5.166 .190 .560 .000 & 4,15 & 0,84 & In Elastis \\
\hline \multicolumn{2}{|c|}{ Jumlah } & 31,31 & $\mathrm{Rp}$ & 23.823.355.010.000 & 16,94 & 7,50 & Elastis \\
\hline \multicolumn{2}{|c|}{ Rata-Rata } & 7,83 & & & 4,24 & 1,88 & Elastis \\
\hline
\end{tabular}

Sumber Data: Badan Pusat Statistik Jawa Timur, data diolah

Data yang diperoleh mencerminkan perubahan pendapatan asli daerah Kabupaten Sumenep menurun dari tahun 2005/2006 2008/2009. Penurunan PAD yang sangat menonjol terlihat pada tahun 2006/2007 yaitu 4,96 persen dari tahun sebelumnya yaitu 18,28 persen. Kemudian pada tahun-berikutnya penurunan PAD tidak terlalu besar. Terbukti pada tabel 2. Hasil perhitungan menunjukkan bahwa persentase perubahan PAD terhadap persentase perubahan PDRB selalu besar yaitu mulai tahun 2005/2006 sampai tahun 2007/2008 dari satu yang berarti berpengaruh positif terhadap penerimaan PAD. Hal ini mengandung arti bahwa penerimaan PAD Kabupaten Sumenep cukup peka terhadap perubahan yang terjadi pada PDRB. Kecuali pada tahun 2008/2009 
elastisitas PAD terhadap PDRB elastis yang berakibatkan tidak peka mengalami penurunan yaitu 0,84 . terhadap perubahan yang terjadi pada Karena nilai elstisitas tersebut kurang PDRB. dari 1 persen maka data tersebut in Tabel 2. Elastisitas penerimaan PAD terhadap PDRB kabupaten Sumenep Tahun 2005/2006-2008/2009

\begin{tabular}{|c|c|c|cc|c|c|c|}
\hline \hline Tahun & PAD & Pertumbuhan PAD (\%) & & PDRB & Pertumbuhan PDRB & Elastisitas (\%) & Keterangan \\
\hline 2005 & Rp32.964.574.000 & & Rp & 4.376 .237 .910 .000 & & & \\
\hline 2006 & Rp38.991.459.000 & 18,28 & $\mathrm{Rp}$ & 4.555 .422 .120 .000 & 4,09 & 4,47 & Elastis \\
\hline 2007 & $\mathrm{Rp} 40.923 .651 .000$ & 4,96 & $\mathrm{Rp}$ & 4.765 .087 .090 .000 & 4,60 & 1,08 & Elastis \\
\hline 2008 & $\mathrm{Rp} 42.795 .564 .000$ & 4,57 & $\mathrm{Rp}$ & 4.960 .417 .330 .000 & 4,10 & 1,12 & Elastis \\
\hline 2009 & $\mathrm{Rp44.292.310.000}$ & 3,50 & $\mathrm{Rp}$ & 5.166 .190 .560 .000 & 4,15 & 0,84 & In Elastis \\
\hline \multicolumn{2}{|c|}{ Jumlah } & 31,31 & $\mathrm{Rp}$ & 23.823 .355 .010 .000 & 16,94 & 7,50 & Elastis \\
\hline \multicolumn{2}{|c|}{ Rata-Rata } & 7,83 & & & 4,24 & 1,88 & Elastis \\
\hline \hline
\end{tabular}

Sumber Data: Badan Pusat Statistik Jawa Timur, data diolah

Nilai elastisitas rata-rata pertahun sebesar 1,88 persen artinya selama empat tahun mulai tahun 2005/2006 sampai 2008/2009, setiap kenaikan sebesar 1 persen akan menyebabkan kenaikan rata-rata penerimaan PAD sebesar 1,88. Demikian sebaliknya, jika terjadi penurunan PDRB sebesar 1 persen maka potensi penerimaan PAD akan mengalami penurunan rata-rata sebesar 1,88 persen.

Sensitifitas perubahan penerimaan pajak dan retribusi terhadap perubahan penduduk perlu di pertahankan dan di tingkatkan melalui intensifikasi dan ektensifikasi PAD. Semakin berperan partisipasi masyarakat dalam membayar pajak dan retribusi daerah akan sangat menunjang terlaksananya derajat otonomi daerah yang tinggi.

\section{PENUTUP}

Berdasarkan hasil pembahasan yang sesaui dengan hasil penelitian maka penulis dapat menyimpulkan sebagai perkembangan pendapatan asli daerah kabupaten sumenep Data yang diperoleh mencerminkan perubahan pendapatan asli daerah Kabupaten Sumenep menurun dari tahun 2005/2006 - 2008/2009. Penurunan PAD pertumbuhan PAD menurun dari tahun ke tahun yang sangat menonjol telihat pada tahun 2006/2007 yaitu 4,96 persen dari tahun sebelumnya yaitu 18,28 persen. Kemudian pada tahunberikutnya penurunan PAD tidak terlalu besar Hal ini mengandung arti bahwa 
penerimaan PAD Kabupaten Sumenep cukup peka terhadap perubahan yang terjadi pada PDRB. Nilai elastisitas rata-rata pertahun sebesar 1,88 persen artinya selama empat tahun mulai tahun 2005/2006 sampai 2008/2009, setiap kenaikan sebesar 1 persen akan menyebabkan kenaikan rata-rata penerimaan PAD sebesar 1,88 Pengamatan atas elastisitas penerimaan pajak dan retribusi di kabupaten Sumenep menunjukkan bahwa besaran pajak daerah menunjukkan nilai yang rendah pada tahun2006, namun pada tahun 2007 mengalami peningkatan 2008 mengalami penurunan, namun pada tahun 2009 mengalami nilai elastisitas kembali meningkat dengan nilai sebesar 7,35 persen. Sebaliknya untuk retribusi daerah menunjukkan nilai elastisitas yang semakin tidak elastis dimana pada akhir periode nilai elastisitasnya hanya -2,26. Nilai elastisitas rata-rata penerimaan pajak terhadap PDRB selama periode pengamatan menunjukkan angka sebesar 1,84 persen. Suatu angka yang elastis. Hal ini mengandung arti bahwa kenaikan PDRB sebesar 1 persen akan diikuti kenaikan penerimaan pajak sebesar 1,84 persen. Sedangkan elastisitas rata - rata penerimaan retribusi terhadap PDRB adalah sebesar 3,79 persen yang berarti bahwa kenaikan PDRB sebesar 1 persen akan menyebabkan kenaikan potensi penerimaan retribusi sebesar 3,79 persen. Dengan demikian. Jika dilihat dari elastisitas rata - rata untuk pajak dan retribusi dapat dikatakan bahwa kabupaten Sumenep mempunyai potensi dasar pajak dan retribusi yang kuat yang dapat dijadikan modal dalam upaya meningkatkan penerimaan daerah.

Untuk meningkatkan penerimaan pendapatan asli daerah terhadap produk domestik regional bruto (PDRB) adalah sebagi berikut, Meningkatkan pertumbuhan Ekonomi Daerah, Menambah obyek retribusi dan Pajak serta intensifikasi sistem pemungutan retribusi dan pajak., Mengkaji ulang realisasi penerimaan pendapatan asli daerah supaya bisa terperinci dan bisa di pahami oleh peneliti,Oleh karena itu banyak potensi pajak serta retribusi daerah yang masih relatif tertinggal, sebaiknya pemerintah kabupaten Sumenep membuat kebijakan agar dapat menaikkan pendapatan asli daerah yang rendah sehingga dapat memperbaiki pola pertumbuhan Ekonomi menjadi lebih baik dan tindakan proaktif.

\section{DAFTAR PUSTAKA}


Abdul Halim, 2002, Akuntansi dan pengendalian Keuangan Daerah, AMP YKPN, Yogyakarta

Anonim, UUD Tahun 1945

Anonim, Undang - Undang No. 18 Tahun 1997 tentang pajak daerah dan retribusi

Anonim, Undang _ Undang Daerah No. 22 Tahun 1999 tentang Pemerintah Daerah. Penerbit Kuraiko Pratama Bandung

BPS Badan Pusat Statistik. Kabupaten Sumnenep

BPS Badan Pusat Statistik Jawa Timur

Davey, Kenneth,1988, Pembiayaan Pemerintah Daerah, Universitas Indonesia Press, Jakarta
Kaho, Riwu, 1999, Peranan Pajak dan Retribusi Daerah dalam era otonomi daerah, publikasi penelitian, Internet.

LPEM Universitas Indonesia bekerjasama dengan Clean Urban Project,RTI (2000), "Laporan Studi Dampak Krisis Ekonomi Terhadap Keuangan Daerah di Indonesia", Jakarta.

Mardiasmo, 2002, paerpajakan, ANDI Yogyakarta. Edisi Revisi

Munawar, Islamil, 2002, Pendapatan Asli Daerah dalam Otonomi Daerah, Jurnal TEMA, Vol III, No I, Universitas Brawijaya Malang. 